\title{
Thymic tumours and their special features
}

\author{
Clémence Basse $\mathrm{B}^{1,2,3,4}$ and Nicolas Girard ${ }^{1,2,3,4}$ \\ Number 11 in the Series "Thoracic oncology" \\ Edited by Rudolf Huber and Peter Dorfmüller
}

${ }^{1}$ Institut du Thorax Curie-Montsouris, Institut Curie, Paris, France. ${ }^{2}$ EURACAN, Centre Léon Bérard, Lyon, France. ${ }^{3}$ Réseau Tumeurs Thymiques et Cancer (RYTHMIC), Gustave Roussy, Villejuif, France. ${ }^{4}$ International Thymic Malignancy Interest Group, Mount Kisco, NY, USA.

Corresponding author: Nicolas Girard (nicolas.girard2@curie.fr)

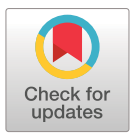

Copyight 202

This version is distributed under the terms of the Creative Commons Attribution NonCommercial Licence 4.0. For commercial reproduction rights and permissions contact permissions@ersnet.org

Received: 19 Jan 2021 Accepted: 2 March 2021

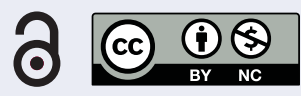

Shareable abstract (@ERSpublications)

Thymic tumours are rare and heterogeneous tumours. Management is based on multidisciplinary discussion and networking. https://bit.ly/3kYAZ7u

Cite this article as: Basse C, Girard N. Thymic tumours and their special features. Eur Respir Rev 2021; 30: 200394 [DOI: 10.1183/16000617.0394-2020].

\section{Abstract}

Thymic tumours are rare thoracic malignancies, that may be aggressive and difficult to treat. The pillars of the management include pathological review, consideration of differential diagnoses, staging and multidisciplinary discussion. Assessment of resectability is key to drive the treatment sequencing. Association with autoimmune diseases, especially myasthenia gravis, is observed, which impacts the oncological management. Networks are being built at the national and international levels. This article provides an overview of the most recent findings in the diagnosis, staging, histology, and management strategies of thymic tumours.

\section{Introduction}

Thymic tumours are rare thoracic malignancies, that may be aggressive and difficult to treat [1]. Although they are the most common tumours in the anterior mediastinal compartment, thymic tumours represent a wide variety of entities, including thymomas, thymic carcinomas, and neuroendocrine thymic tumours (NETTs) [2]. The reported annual incidence ranges from 1.3 to 3.2 per million [1]. The mean age at diagnosis is $40-50$ years old, but thymic tumours may actually be diagnosed in children as well as in elderly patients. The pathogenesis is virtually unknown, as no environmental or infectious factors have been demonstrated to be associated with these tumours. Association with autoimmune diseases, especially myasthenia gravis, is observed, what impacts the oncological management [3].

In the past decade, the scientific community has been increasingly interested in thymic malignancies, resulting in the creation of many dedicated working groups, including the International Thymic Malignancy Interest Group (ITMIG; www.itmig.org), or local organisations, such as the RYTHMIC (Réseau tumeurs THYMiques et Cancer; www.rythmic.org) network in France. These networks provide the opportunity of setting up databases with a long-term follow-up of patients This article provides an overview of the most recent findings in the diagnosis, staging, histology, and management strategies of thymic tumours.

The three pillars for the management of thymic tumours

\section{Make sure of the diagnosis: imaging}

The first step for the diagnosis of thymic tumours point is to make the differential diagnosis with other anterior mediastinal tumours, and non-malignant thymic lesions [4], using computed tomography (CT). The need for pre-treatment biopsy depends on whether the tumour is resectable upfront $[1,3,5]$. Thymic epithelial tumours (TETs) are the most frequent cause of anterior mediastinal mass, accounting for 35\% of cases; other differential diagnoses include lymphomas (25\% of cases), and germ-cell tumours, malignant or not (20\% of cases) [6]; pathologically, thymic carcinoma has to be differentiated from lung squamous cell carcinoma, as well as from more rare entities, such as NUT-rearranged midline carcinomas [7]. 
Thymic lesion is then the most frequent diagnosis to consider when autoimmune disease is observed, especially myasthenia gravis [8]. In such situation, the second step is to differentiate thymic malignancy from hyperplasia or non-involuted thymus, what may be challenging. Thymic rebound hyperplasia has actually to be considered after stress, or most frequently corticosteroids or antihormonal treatment. Thymic lymphoid hyperplasia is observed in the setting of hyperthyroidism, conjunctive tissue or vascular disease, but also myasthenia gravis. CT features include low-attenuation, symmetric, and fatty pattern maintaining the bi-pyramidal shape of the thymus [9]. Chemical-shift MRI (as per Dixon's proposals) may detect fatty infiltration showing homogeneous signal decrease on opposed phase images relative to in-phase images, that is never seen in thymoma [9]. 18-fluorodesoxyglucose positron-emission tomography (PET)-scan is not recommended for thymic masses. Thymic hyperplasia may present with hypermetabolism [10]. A PET-scan may be optional in case of tumours with aggressive histology and advanced stage to further characterise subsequent lesions suspicious for recurrences.

\section{Make sure of the diagnosis: histopathology}

TETs are categorised histologically according to the World Health Organization (WHO) histological classification [2], recently updated in 2015 based on a consensus statement of ITMIG published in 2014 [11]. The classification distinguishes thymomas from thymic carcinomas; thymomas are further subdivided into different types (so-called A, AB, B1, B2, and B3) based upon the morphology of epithelial tumour cells (polygonal or spindle cells), the relative proportion of the non-tumoural lymphocytic component (decreasing from type B1 to B3), and resemblance to normal thymic architecture [2, 3]. Thymic carcinomas are similar to their extrathymic counterpart, and the most frequent subtype is squamous cell carcinoma; NETTs are very rare, with a management based on that proposed for other neuroendocrine tumours, and will not be further discussed in this article. While the interobserver reproducibility of the WHO classification has been questioned over time [12], the ITMIG consensus statement proposes major and minor morphological and immunohistochemical criteria to better individualise each TET entity; these criteria were defined based on a series of 58 prototypic and difficult-to-classify TETs [2]. Histologically, thymic carcinomas may be distinguished from primary lung carcinomas; a recommendation facing an intrathoracic carcinoma, especially with squamous cell subtype, is to perform immunohistochemistry for CD5 and CD117 which is exclusively observed in primary squamous cell thymic carcinoma [13]. Ultimately, an updated WHO classification publication is expected in 2021.

Pathologic central review of patients diagnosed with TET is recommended, as it ensures a better quality of diagnosis; from the RYTHMIC network experience of systematic review in 467 cases by a panel of 10 expert pathologists, histology was modified in nearly one third of patients [6].

\section{Staging: from Masaoka-Koga to TNM}

TETs were historically staged according to the Masaoka-Koga staging system (table 1) [14, 15], which is correlated with overall survival [16]. Masaoka-Koga staging is actually a surgical pathology system that is assessable only after surgical resection of the tumour. A unique feature of TETs is that the WHO classification is correlated with stage at diagnosis, what may explain its reported prognostic value [12]; indeed, the histopathological subtypes, from type A to type B3, are associated with more aggressive pattern [12].

The 8th Tumour Node Metastasis (TNM)-based staging system adopted by the American Joint Committee on Cancer/Union Internationale Contre le Cancer consortium, is now standard for thymic malignancies, based on overall survival analyses of a retrospective international database of more than 10000 cases [17]. In this staging system, all Masaoka stage I, II, and some stage III TETs are merged together with stage I tumours, based on their similar prognosis; TNM stage II are defined by pericardium invasion; TNM stage III tumours are further subdivided into 2 groups (T3 and T4), aiming at providing more help in formalising resectability, a major driver of the treatment strategy in advanced TETs [1, 3]. Given the magnitude of data generated based on the Masaoka-Koga system, the two staging systems should be assessed for patients to help the decision making, especially for surgical and postoperative management.

There is then no clinical staging system for TETs, meaning no staging based only on imaging, which may not assess pericardial invasion, and the treatment strategy is then primarily based on whether the tumour may be resected upfront or not, as complete resection represents the most consistent and significant prognostic factor on disease-free and overall survival [15, 16]. Correlation between clinical and pathological stage is better in advanced stages, given the identification at imaging of vessel invasion, enlarged lymph nodes, pleural/pericardial lesions, or even systemic metastases [18]. 
TABLE 1 Staging of thymic tumours according to 8th Tumour Node Metastasis (TNM), and Masaoka-Koga staging systems

\begin{tabular}{|c|c|c|}
\hline \multicolumn{2}{|l|}{ Stage } & \multirow[t]{2}{*}{ Descriptors } \\
\hline \multicolumn{2}{|c|}{ Tumour } & \\
\hline \multirow[t]{2}{*}{$\mathrm{T} 1$} & T1a & $\begin{array}{l}\text { Encapsulated or unencapsulated, with or without extension into the } \\
\text { mediastinal fat }\end{array}$ \\
\hline & $\mathrm{T} 1 \mathrm{~b}$ & Extension into the mediastinal pleura \\
\hline $\mathrm{T} 2$ & & Direct invasion of the pericardium (partial or full-thickness) \\
\hline T3 & & $\begin{array}{l}\text { Direct invasion of the lung, the brachiocephalic vein, the superior vena cava, } \\
\text { the chest wall, the phrenic nerve, and/or hilar (extrapericardial) pulmonary } \\
\text { vessels }\end{array}$ \\
\hline T4 & & $\begin{array}{l}\text { Direct invasion of the aorta, arch vessels, the main pulmonary artery, the } \\
\text { myocardium, the trachea, or the oesophagus }\end{array}$ \\
\hline \multicolumn{3}{|l|}{ Node } \\
\hline NO & & No No nodal involvement \\
\hline N1 & & $\begin{array}{l}\text { N1 Anterior (perithymic) nodes (IASLC levels 1, 3a, } 6 \text { and/or } \\
\text { supradiaphragmatic/inferior phrenics/pericardial) }\end{array}$ \\
\hline N2 & & $\begin{array}{l}\text { N2 Deep intrathoracic or cervical nodes (IASLC levels 2, 4, 5, 7, 10, and/or } \\
\text { internal mammary nodes) }\end{array}$ \\
\hline \multicolumn{3}{|r|}{ (6) } \\
\hline M0 & & No metastatic pleural, pericardial, or distant sites \\
\hline \multirow[t]{2}{*}{ M1 } & M1a & Separate pleural or pericardial nodule(s) \\
\hline & M1b & Pulmonary intraparenchymal nodule or distant organ metastasis \\
\hline
\end{tabular}

\section{Stage grouping}

Corresponding Masaoka-Koga stage

\begin{tabular}{lll}
\hline I & T1NOM0 & I, IIA, IIB, III \\
II & T2N0M0 & III \\
IIIa & T3N0M0 & III \\
IIIb & T4N0M0 & III \\
IVa & T any N0,1 M0,1a & IVA, IVB \\
IVb & T any N0-2 M0-1b & IVB \\
\hline
\end{tabular}

IASLC: International Association for the Study of Lung Cancer.

\section{Multidisciplinary tumour board is mandatory}

The management of patients with TETs requires continuous multidisciplinary expertise at any step of the disease [1]. The assessment of resectability is mostly based on the surgeon expertise, but may be complex, even if the 8th TNM staging allows a better definition of resectable anatomical structures (stage IIIA). Ultimately, stage IV disease does not mean that the tumour is not amenable to complete surgical resection, especially in the setting of pleural implants [19, 20]. Multidisciplinary tumour board is then highly valuable at any stage of the disease.

In France, RYTHMIC is a nationwide network dedicated to thymic tumours, which was recognised by the French National Cancer Institute, in 2012 [21-23]. The treatment of all patients with TET is discussed on a real-time basis at a national multidisciplinary tumour board, which is organised twice a month basis using a web-based system. Decision-making is based on consensual recommendations, that were originally established based on available evidence, and are updated and approved each year by all members of the network [1]. Similar thymoma-dedicated networks are now being implemented in France and in other European countries, such as Spain and Italy (the TYME collaborative group) [21, 24].

Across Europe, similar networking has been recognised. A European Reference Network (ERN) EURACAN (European Rare Cancer Network) domain is dedicated to rare thoracic tumours, and handles a network of 100+ healthcare providers; the objectives of EURACAN include the updating of current guidelines, educational programmes, dissemination and communication with patient advocacy groups, and the establishment of research projects. The Clinical Patient Management System (CPMS) is a EU-sponsored web-based platform that allows the discussion of patient cases with multidisciplinary experts from the ERNs.

ITMIG (International Thymic Malignancy Interest Group) was created in 2010 and was endorsed and supported by the most representative medical and surgical societies around the globe [25]. The mission of 
ITMIG is to promote the advancement of clinical and basic science related to thymic malignancies. It provides infrastructure for international cooperation, maintains close collaboration with other related organisations, and facilitates the spread of knowledge about thymic neoplasms. An international virtual tumour board is organised on a monthly basis.

\section{Resectable TETs: surgery and postoperative radiotherapy}

In Masaoka-Koga stage I/II and some stage III tumours (classified as stage I, II, IIIA in the 8th TNM system), complete resection is usually achievable upfront, and surgery represents the first step of the treatment, possibly followed by postoperative radiotherapy [1, 3, 26, 27].

\section{Surgery principles}

Standard approach is median sternotomy, that allows the wide opening of the mediastinum and both pleural cavities, followed by assessment of macroscopic capsular invasion, infiltration of mediastinal fat, adherences, and involvement of surrounding tissues. Generally, complete thymectomy, including the tumour, the residual thymus, and perithymic fat, is preferred because local recurrences have been observed after partial thymectomy; thymomectomy alone is debatable [28]. If the tumour is invasive, en bloc removal of all affected structures, including lung parenchyma, usually through limited resection, great vessels, nerves, and pleural implants, should be performed. Areas of uncertain margins are marked with clips to allow precise delivery of postoperative radiotherapy [27]. Phrenic preservation does not affect overall survival but increases the risk of local recurrence [29], and may be balanced with the achievement of complete resection especially in patients with severe myasthenia gravis. Frozen sections to assess tumour involvement of resection margins are not recommended, as differentiating tumoural thymic epithelial cells from non-tumoural thymic epithelial cells is difficult on such specimens [2].

Minimally invasive surgery is becoming standard for stage I tumours in the hands of appropriately trained surgeons [30-32]. This includes transcervical, extended transcervical, video-assisted thoracoscopy, and robotic approaches (right or left, right and left, right and cervical, left and cervical, subxiphoid and right and left, cervical and subxiphoid). The choice for minimally invasive resection should not degrade or change the principles that are deemed appropriate for an open approach, especially the achievement of complete resection that ultimately may require conversion to open surgery.

Ultimately, communication between surgeons and pathologists is crucial for staging TETs [27]. The proper orientation of the specimen and the marking of involved structures, organs or areas of concern are done by operating surgeons, and may be done using a mediastinal board. Routine removal of anterior mediastinal nodes is recommended [33]. Systematic sampling of intrathoracic sites is encouraged (i.e. paratracheal, aortopulmonary window, subcarinal areas depending on tumour location) in stage III/IV tumours. The actual need and the importance of nodal resection remains highly debated [33].

In stage IVA thymoma, defined as intrapleural or intrapericardial dissemination of tumour cells without any distant metastasis, surgical options, in addition to thymectomy, are local pleura or pericardium resection, may include total pleurectomy, and pleuropneumonectomy [34, 35]. Although it seems to be a very aggressive approach, pleuropneumonectomy has been shown to be feasible with good outcomes in these patients. Intrathoracic chemohyperthermia (ITCH, or HITHOC: hyperthermic intra operative thoraco-abdominal chemotherapy) based on Cisplatin (from 50 to $100 \mathrm{mg} \cdot \mathrm{m}^{-2}$ ) and possibly associated with other agents, associated with subtotal pleural decortication is feasible, but requires to be prospectively assessed [35].

Debulking has been defined as removing $90 \%$ or more of tumour burden [36, 37]. The indication of debulking still remains controversial but may be proposed in non resectable thymomas only, not carcinomas, with clearly inferior results as compared to standard, carcinologic surgery. Some authors advocate the place of debulking to improve efficacy of high doses radiotherapy by minimising fields and showed significantly better survival in stages III and even IVA.

\section{Postoperative radiotherapy}

Given the tendency of TETs towards local and regional recurrence, and their established radio-sensitivity, radiotherapy has historically been a component in the treatment strategy in the postoperative setting $[1,3,5]$.

Current modalities of postoperative radiotherapy for thymic epithelial tumours include 1) the use of multi-field arrangement conformal radiotherapy and three-dimensional treatment planning [38]; 2) a clinical target volume including the whole thymic space, the tumour and its extensions, and the anterior, superior, and middle mediastinum; 3) a total dose of 45-50 Gy after complete resection, 50-54 Gy after 
R1 resection, with a boost on areas of concern, as mentioned, surgical clips may be then useful to plan the gross tumour volume; and 4) the use of a standard-fractionation scheme consisting of daily doses from 1.8 to 2 Gy over a 4-6-week period. Proton-beam radiotherapy has also been used in the postoperative setting.

Unfortunately, the rarity of TETs, and the lack of prospective, randomised trials, make it difficult to draw high-level evidence-based recommendations regarding its actual efficacy in terms of reduction of the risk of recurrence and death. Evidence from retrospective series indicates: 1) the absence of survival benefit after radiotherapy in stage I thymoma, and a debatable survival benefit after R0 resection of stage II-III thymoma [39]; 2) a similar rate of recurrence whether or not patients received postoperative radiotherapy after complete resection of thymoma [40]; and 3) a recurrence-free and overall survival benefit after resection of thymic carcinoma $[41,42]$. The recurrences actually occur mostly in the intrathoracic pleura, rather than in the mediastinal tumour bed [43].

In the ITMIG database report that included 1263 patients with completely resected (R0) stage II or III thymoma enrolled in a retrospective setting, postoperative radiotherapy (PORT) had been given to 55\% of patients, and the 5- and 10-year overall survival rates for patients having undergone an operation plus PORT were $95 \%$ and $86 \%$, respectively, compared with $90 \%$ and $79 \%$ for patients receiving an alone operation $(p=0.002)$. This overall survival benefit remained significant when patients with stage II $(\mathrm{p}=0.02)$ and stage III thymoma $(\mathrm{p}=0.0005)$ were analysed separately [44]. However, there are major limitations in this analysis including its retrospective nature, the absence of a systematic review in the tumour staging, a potential heterogeneity among PORT indications from one centre to another, the imbalance in stage II versus stage III tumours in the surgery plus PORT versus the alone surgery groups (with higher stage being a strong decision factor which favours PORT), but mostly the overall survival analysis, when more than the half of deaths are not related to tumour progression [45]. Other large data base studies from the US or Asia have shown an impact of PORT on survival of stage II or III thymoma [46-49]. Especially, similar results were obtained from the analysis of the National Cancer Database in the US [47]. In the Japanese cohort of 1110 thymomas, PORT was not identified as a significant factor influencing overall survival [46]. Of note, those data are all based on the Masaoka-Koga staging system.

Current recommendations are the following: PORT is not indicated after complete resection of MasaokaKoga stage I thymoma [1], and is routinely not recommended after complete resection of stage II thymoma; still, PORT may be considered in case of aggressive histology (type B2, B3) or transcapsular invasion (stage IIB). Postoperative radiotherapy is recommended after complete resection of stage III/IVA thymoma, and in thymic carcinomas, whatever is the stage; it is also delivered in case of microscopically (R1) or macroscopically incomplete (R2) resection.

\section{Advanced TETs: systemic therapies}

In Masaoka-Koga stage III/IVA tumours (classified as stage IIIA/IIIB/IVA in the 8th TNM proposed system), complete resection is usually no achievable upfront. A biopsy is performed, followed by primary/ induction chemotherapy, in a curative-intent setting with subsequent surgery or radiotherapy [1, 3, 5, 50]. Cases not eligible for local treatment receive definitive chemotherapy.

\section{Primary chemotherapy}

Primary/induction chemotherapy is recommended in non-resectable advanced TETs [51-55]. Cisplatin-based combination regimens should be administered; combinations of cisplatin, adriamycin, and cyclophosphamide, and cisplatin and etoposide are recommended [1, 3, 5]. Primary chemoradiotherapy with platin and etoposide is an option, especially for thymic carcinomas or if the tumour is never expected to become eligible for surgical resection [56, 57].

Usually 2-4 cycles are administered before imaging is performed to reassess resectability of the tumour. Surgery should be offered to patients for whom complete resection is thought to be achievable, according to above discussed principles; extended resection may be required [58]. Postoperative radiotherapy is then usually delivered.

\section{Definitive radiotherapy}

When the patient is not deemed to be a surgical candidate, either because R0 resection is not thought to be achievable, definitive radiotherapy is recommended part of a sequential chemoradiotherapy strategy [55]. Combination with chemotherapy (including cisplatin, etoposide chemotherapy and a total dose of radiation of 60 Gy) may be considered [56]. 


\section{Exclusive chemotherapy}

Chemotherapy should be offered as the single modality treatment in advanced, non-resectable, non-irradiable or metastatic (stage IVB) TETs to improve tumour-related symptoms the aim is to improve tumour-related symptoms through obtention of tumour response, while no prolonged survival is uncertain. Cisplatin-based combination regimen should be administered [51, 57, 59-62]. No randomised studies have been conducted, and it is unclear which regimens are best; multi-agent combination regimens and anthracycline-based regimens appear to have improved response rates compared to others, especially the etoposide, ifosfamide and cisplatin combination [63, 64]; still response is hard to assess given the location of target lesions, and criteria have been recommended for pleural lesions include the use of short axis as the measurement plane, and the unidimensional measurement of two pleural tumour sites at three different levels [65]. Combinations of cisplatin, adriamycin, and cyclophosphamide is preferred. Combination of carboplatin and paclitaxel is an option for thymic carcinoma [60, 62].

Overall, ll consecutive patients for whom systemic treatment was discussed at the RYTHMIC Multidisciplinary Tumour Board from 2012 to 2015 and who received at least one cycle of treatment were analysed in a landmark study [64]. A total of 236 patients were included in this analysis. 91 patients received primary chemotherapy, leading to a response rate of $79 \%$, and a median progression-free survival (PFS) of 23.2 months. Predictors of longer PFS were histology of thymoma and cyclophosphamide, adriamycin and platin regimen. Exclusive chemotherapy was delivered to 54 patients. Response rate was 35\% and was higher with PAC regimen. Median PFS was 6.2 months, and was correlated to response rate.

\section{Recurrent TETs}

Recurrences of TETs are treated with an algorithm that is similar to that of newly diagnosed tumours. Complete resection of recurrent TET is a major predictor survival [66-68], and surgery is performed in case of resectable lesion, especially occurring in the pleura.

\section{Systemic chemotherapy}

In non-resectable recurrences, several consecutive lines of systemic treatment are delivered. PAC chemotherapy may be re-administered [64]. Preferred regimens for second-line treatment include carboplatin plus paclitaxel [60], and platin plus etoposide [57]. Options for subsequent lines include pemetrexed $\left(500 \mathrm{mg} \cdot \mathrm{m}^{-2} \cdot 3\right.$ weeks ${ }^{-1}$ ) [69], oral etoposide (100 mg daily). In the RYTHMIC cohort, chemotherapy for 1st, 2nd, 3rd and 4th recurrence was delivered to 114, 81, 51 and 27 patients, respectively [64]. Response rates ranged between 11 and 25\%. Median PFS were 7.7, 6.2, 5.9, and 6.5 months, respectively.

\section{Targeted agents}

The carcinogenesis mechanisms of TETs are virtually unknown [70, 71]. Resistance to apoptosis is associated with copy number gains of the anti-apoptotic molecule BCL2. Deregulation of cell-cycle controlling molecules, including copy number loss of $C D K N 2 A / B$, hypermethylation of its promoter, is associated with a lack of expression of its related protein p16INK4. Activation of the PI3K-AKT-MTOR pathway and deleterious mutations of regulatory subunits of the PI3K gene, as well as activating mutation of the KIT gene in thymic carcinomas are identified [70-75].

In the clinic, the relevance of KIT mutations as a therapeutic target remains has to integrate that all of these are not be uniformly sensitive to available KIT inhibitors. KIT expression at immunohistochemistry is a hallmark, possibly a diagnostic marker, of thymic carcinomas and does not correlate with the occurrence of a KIT mutations. Single case reports of responses with the use KIT inhibitors, imatinib, sunitinib, or sorafenib, are published $[1,71]$.

Everolimus was assessed in a phase II trial enrolling 51 patients [76]. Stable disease was the most frequent response pattern, with disease control rate of $88 \%$.

\section{Anti-angiogenic agents}

Multikinase inhibitors targeting KIT, such as imatinib and sunitinib, are also potent angiogenesis inhibitors. Sunitinib is considered an option for refractory TETs, based on the results of two phase II trials showing high disease control rates above $80 \%$ in thymoma and thymic carcinoma [77, 78]. In a retrospective cohort from RYTHMIC, sunitinib was delivered beyond fourth line treatment [79]. Lenvatinib is another antiangiogenic drug, that has been approved in Japan for the treatment of advanced, regractory thymic malignancies [80]. 
Hot topic: immunotherapy

\section{Immune-related characteristics}

One-third of patients diagnosed with thymoma present with autoimmune disorders, the most frequent being myasthenia gravis [1]. Other frequent disorders include pure red cell aplasia (5\% of cases), and hypogammaglobulinaemia (5\% of cases). Thymic carcinomas are not associated with such disorders. Carcinogenesis then disrupts the thymus physiological role of controlling central tolerance to self-antigens, with the positive and negative selection of immature T cells [81]. Medullary thymic tumour epithelial cells present with inabilities to express tissue-related antigens, related to a loss of expression of the transcription factor AIRE (autoimmune regulator), similar to what occurs in APECED (autoimmune polyendocrinopathy candidiasis ectodermal dystrophy).

PD-L1 expression is a hallmark of thymic epithelial cells, and such expression is not related to antitumour immune response nor as a predictive biomarker of efficacy for immune checkpoint inhibitors targeting PD-1 or PD-L1 [82, 83]. Tumour mutation burden is low both in thymomas and thymic carcinomas [74, 75].

PD-1/PD-L1 inhibitors in patients with advanced TETs were assessed in 4 trials.

A phase II trial with pembrolizumab enrolled 41 patients with thymic carcinomas [84], 15\% of whom developed severe immune related adverse events, including polymyositis and myocarditis, pancreatitis, hepatitis, diabetes mellitus type 1 , or bullous pemphigoid. Response rate was $23 \%$. A similar trial was conducted in Korea [85], both in thymic carcinomas and thymomas. Results were similar. A phase II trial with nivolumab failed to achieve clinical significance. A phase I trial with avelumab [86, 87] was conducted mostly in thymomas; three patients showed response after a single dose of treatment. Treatment was discontinued in five patients for toxicities.

Overall, immunotherapy is effective in thymic carcinomas, with a concern for toxicities leading extensive baseline immune check-up to be recommended. Trials are ongoing, such as those assessing nivolumab (NIVOTHYM) or pembrolizumab (PECATI)-based regimens.

\section{Conclusion}

Thymic malignancies are rare cancers, with complex classifications and treatment strategies based on multidisciplinary expertise and consensus. Lack of clinical trials and access to new therapies is a concern. Many academic groups are launching initiatives and projects, making the field very active and a model of implementation for orphan cancers.

Provenance: Commissioned article, peer reviewed.

Previous articles in this series: No. 1: Eichhorn F, Winter H. How to handle oligometastatic disease in nonsmall cell lung cancer. Eur Respir Rev 2021; 30: 200234. No. 2: Asciak R, George V, Rahman NM. Update on biology and management of mesothelioma. Eur Respir Rev 2021; 30: 200226. No. 3: Finazzi T, Schneiders FL, Senan S. Developments in radiation techniques for thoracic malignancies. Eur Respir Rev 2021; 30: 200224. No. 4: Huber RM, Kauffmann-Guerrero D, Hoffmann $\mathrm{H}$, et al. New developments in locally advanced nonsmall cell lung cancer. Eur Respir Rev 2021; 30: 200227. No. 5: Rittmeyer A, Schiwitza A, Sahovic L, et al. Update on recent key publications in lung oncology: picking up speed. Eur Respir Rev 2021; 30: 200300. No. 6: Abdayem P, Planchard D. Update on molecular pathology and role of liquid biopsy in nonsmall cell lung cancer. Eur Respir Rev 2021; 30: 200294. No. 7: Lam S, Tammemagi M. Contemporary issues in the implementation of lung cancer screening. Eur Respir Rev 2021; 30: 200288. No. 8: Ghigna M-R, Thomas de Montpreville V. Mediastinal tumours and pseudo-tumours: a comprehensive review with emphasis on multidisciplinary approach. Eur Respir Rev 2021; 30: 200309. No. 9: Remon J, Facchinetti F, Besse B. The efficacy of immune checkpoint inhibitors in thoracic malignancies. Eur Respir Rev 2021; 30: 200387. No. 10: Benusiglio PR, Fallet V, Sanchis-Borja M, et al. Lung cancer is also a hereditary disease: a review. Eur Respir Rev 2021; 30: 210045.

Conflict of interest: C. Girard has nothing to disclose. N. Basse has nothing to disclose.

\section{References}

1 Girard N, Ruffini E, Marx A, et al. Thymic epithelial tumours: ESMO clinical practice guidelines for diagnosis, treatment and follow-up. Ann Oncol 2015; 26: Suppl. 5, v40-v55.

2 WHO histological classification of tumours of the thymus. In: Travis WB, Brambilla A, Burke AP, et al., eds. World Health Organization classification of tumours of the lung, pleura, thymus and heart. Lyon, IARC Press, 2015. 
3 Girard N, Mornex F, Van Houtte P, et al. Thymoma: a focus on current therapeutic management. J Thorac Oncol 2009; 4: 119-126.

4 Carter BW, Marom EM, Detterbeck FC. Approaching the patient with an anterior mediastinal mass: a guide for clinicians. J Thorac Oncol 2014; 9: S102-S109.

5 Falkson CB, Bezjak A, Darling G, et al. The management of thymoma: a systematic review and practice guideline. J Thorac Oncol 2009; 4: 911-919.

6 Molina TJ, Bluthgen MV, Chalabreysse L, et al. Impact of expert pathologic review of thymic epithelial tumors on diagnosis and management in a real-life setting: a RYTHMIC study. Eur J Cancer 2021; 143: 158e167.

7 Evans AG, French CA, Cameron MJ, et al. Pathologic characteristics of NUT midline carcinoma arising in the mediastinum. Am J Surg Pathol 2012; 36: 1222-1227.

8 Carter BW, Benveniste MF, Madan R, et al. ITMIG classification of mediastinal compartments and multidisciplinary approach to mediastinal masses. Radiographics 2017; 37: 413-436.

9 Priola AM, Priola SM, Ciccone G, et al. Differentiation of rebound and lymphoid thymic hyperplasia from anterior mediastinal tumors with dual-echo chemical-shift MR imaging in adulthood: Reliability of the chemical-shift ratio and signal intensity index. Radiology 2015; 274: 238-249.

10 Kerpel A, Beytelman A, Ofek E, et al. Magnetic resonance imaging for the follow-up of treated thymic epithelial malignancies. J Thorac Imaging 2019; 34: 345-350.

11 Marx A, Ströbel P, Badve SS, et al. ITMIG consensus statement on the use of the WHO histological classification of thymoma and thymic carcinoma: Refined definitions, histological criteria, and reporting. J Thorac Oncol 2014; 9: 596-611.

12 Meurgey A, Girard N, Merveilleux du Vignaux C, et al. Assessment of the ITMIG statement on the WHO histological classification and of the eighth TNM staging of thymic epithelial tumors of a series of 188 thymic epithelial tumors. J Thorac Oncol 2017; 12: 1571-1581.

13 Asirvatham JR, Esposito MJ, Bhuiya TA, et al. Role of PAX-8, CD5, and CD117 in distinguishing thymic carcinoma from poorly differentiated lung carcinoma. Appl Immunohistochem Mol Morphol 2014; 22: 372-376.

14 Koga K, Matsuno $\mathrm{Y}$, Noguchi M, et al. A review of 79 thymomas: Modification of staging system and reappraisal of conventional division into invasive and non-invasive thymoma. Pathol Int 1994; 44: 359-367.

15 Detterbeck F, Nicholson AG, Kondo K, et al. The Masaoka-Koga stage classification for thymic malignancies: Clarification and definition of terms. J Thoracic Oncol 2011; 6: S1710-S1716.

16 Detterbeck F, Youssef S, Ruffini E, et al. A review of prognostic factors in thymic malignancies. $J$ Thorac Oncol 2011; 6: S1698-S1704.

17 Thymic tumors. In: Brierley JD, Gosporadowicz MK, Wittekind C, eds. TNM classification of malignant tumours. 8th Edn. Oxford, Wiley and Sons, 2017.

18 Marom EM, Milito MA, Moran CA, et al. Computed tomography findings predicting invasiveness of thymoma. J Thorac Oncol 2011; 6: 1274-1281.

19 Corsini EM, Mitchell KG, Hofstetter WL, et al. Importance of resection for locoregional disease control in Masaoka stage IVA thymic neoplasms. J Surg Oncol 2020; 122: 515-522.

20 Wright CD, Choi NC, Wain JC, et al. Induction chemoradiotherapy followed by resection for locally advanced Masaoka stage III and IVA thymic tumors. Ann Thorac Surg 2008; 85: 385-389.

21 Imbimbo M, Maury JM, Garassino M, et al. Mesothelioma and thymic tumors: Treatment challenges in (outside) a network setting. Eur J Surg Oncol 2019; 45: 75-80.

22 Basse C, Thureau S, Bota S, et al. Multidisciplinary tumor board decision making for postoperative radiotherapy in thymic epithelial tumors: Insights from the RYTHMIC prospective cohort. J Thorac Oncol 2017; 12: $1715-1722$.

23 Remon J, Girard N, Mazieres J, et al. Sunitinib in patients with advanced thymic malignancies: Cohort from the French RYTHMIC network. Lung Cancer 2016; 97: 99-104.

24 Imbimbo M, Ottaviano M, Vitali M, et al. Best practices for the management of thymic epithelial tumors: A position paper by the Italian collaborative group for ThYmic MalignanciEs (TYME). Cancer Treat Rev 2018; 71: 76-87.

25 Detterbeck F. Report of ITMIG 2015 meeting. J Thorac Dis 2015; 7: Suppl. 3, S177-S179.

26 Davenport E, Malthaner RA. The role of surgery in the management of Thymoma: a systematic review. Ann Thorac Surg 2008; 86: 673-684.

27 Detterbeck FC, Moran C, Huang J, et al. Which way is up? Policies and procedures for surgeons and pathologists regarding resection specimens of thymic malignancy. J Thoracic Oncol 2011; 6: S1730-S1738.

28 Fiorelli A, Natale G, Freda C, et al. Is thymomectomy equivalent to complete thymectomy in non-myasthenic patients with early-stage thymoma? Interact Cardiovasc Thorac Surg 2019; 28: 399-403.

29 Hamdi S, Mercier O, Fadel E, et al. Is sacrifying the phrenic nerve during thymoma resection worthwhile? Eur J Cardiothorac Surg 2014; 45: e151-e155.

30 Yang CJ, Hurd J, Shah SA, et al. A national analysis of open versus minimally invasive thymectomy for stage to III thymoma. J Thorac Cardiovasc Surg 2020; 160: 555-567. 
31 Marulli G, Rea F, Melfi $F$, et al. Robot-aided thoracoscopic thymectomy for early-stage thymoma: a multicenter European study. J Thorac Cardiovasc Surg 2012; 144: 1125-1130.

32 Toker A, Sonett J, Zielinski M, et al. Standard terms, definitions, and policies for minimally invasive resection of thymoma. J Thorac Oncol 2011; 6: S1739-S1742.

33 Weksler B, Holden A, Sullivan JL. Impact of positive nodal metastases in patients with thymic carcinoma and thymic neuroendocrine tumors. J Thorac Oncol 2015; 10: 1642-1647.

34 Maury JM, Drevet G, Collaud S, et al. Cytoreductive pleurectomy and intrathoracic chemohyperthermia for pleural relapse of thymomas. Ann Thorac Surg 2019; 107: e157-e160.

35 Yellin A, Simansky DA, Ben-Avi R, et al. Resection and heated pleural chemoperfusion in patients with thymic epithelial malignant disease and pleural spread: a single-institution experience. J Thorac Cardiovasc Surg 2013; 145: 83-87.

36 Hamaji M, Kojima F, Omasa M, et al. A meta-analysis of debulking surgery versus surgical biopsy for unresectable thymoma. Eur J Cardiothorac Surg 2015; 47: 602-607.

37 Fan C, Ge H, Zhang S, et al. Impact of definitive radiotherapy and surgical debulking on treatment outcome and prognosis for locally advanced Masaoka-Koga stage III thymoma. Sci Rep 2020; 10: 1735.

38 Gomez D, Komaki R, Yu J, et al. Radiation therapy definitions and reporting guidelines for thymic malignancies. J Thorac Oncol 2011; 6: Suppl. 3, S1743-S1748.

39 Forquer JA, Rong N, Fakiris AJ, et al. Postoperative radiotherapy after surgical resection of thymoma: Differing roles in localised and regional disease. Int J Radiat Oncol Biol Phys 2010; 76: 440-445.

40 Korst RJ, Kansler AL, Christos PJ, et al. Adjuvant radiotherapy for thymic epithelial tumors: a systematic review and meta-analysis. Ann Thorac Surg 2009; 87: 1641-1647.

41 Ahmad U, Yao X, Detterbeck F, et al. Thymic carcinoma outcomes and prognosis: Results of an international analysis. J Thorac Cardiovasc Surg 2015; 149: 95-100.

42 Ruffini E, Detterbeck F, Van Raemdonck D, et al. Thymic carcinoma: a cohort study of patients from the European society of thoracic surgeons database. J Thorac Oncol 2014; 9: 541-548.

43 Rimner A, Gomez DR, Wu AJ, et al. Failure patterns relative to radiation treatment fields for stage II-IV thymoma. J Thorac Oncol 2014; 9: 403-409.

44 Rimner A, Yao X, Huang J, et al. Postoperative radiation therapy is associated with longer overall survival in completely resected stage II and III thymoma-an analysis of the international thymic malignancies interest group retrospective database. J Thorac Oncol 2016; 11: 1785-1792.

45 Huang J, Detterbeck FC, Wang Z, et al. Standard outcome measures for thymic malignancies. J Thorac Oncol 2011; 6: Suppl. 3, S1691-S1697.

46 Omasa M, Date H, Sozu T, et al. Postoperative radiotherapy is effective for thymic carcinoma but not for thymoma in stage II and III thymic epithelial tumors: The Japanese Association for Research on the Thymus Database Study. Cancer 2015; 121: 1008-1016.

47 Boothe D, Orton A, Thorpe C, et al. Postoperative radiotherapy in locally invasive malignancies of the thymus: Patterns of care and survival. J Thorac Oncol 2016; 11: 2218-2226.

48 Jackson MW, Palma DA, Camidge DR, et al. The impact of postoperative radiotherapy for thymoma and thymic carcinoma. J Thorac Oncol 2017; 12: 734-744.

49 Zhou D, Deng XF, Liu QX, et al. The effectiveness of postoperative radiotherapy in patients with completely resected thymoma: A meta-analysis. Ann Thorac Surg 2016; 101: 305-310.

50 Girard N, Lal R, Wakelee $\mathrm{H}$, et al. Chemotherapy definitions and policies for thymic malignancies. $J$ Thorac Oncol 2011; 6: S1749-S1755.

51 Loehrer PJ, Sr, Kim K, Aisner SC, et al. Cisplatin plus doxorubicin plus cyclophosphamide in metastatic or recurrent thymoma: Final results of an intergroup trial. The Eastern Cooperative Oncology Group, Southwest Oncology Group, and Southeastern Cancer Study Group. J Clin Oncol 1994; 12: 1164-1168.

52 Kim ES, Putnam JB, Komaki R, et al. Phase II study of a multidisciplinary approach with induction chemotherapy, followed by surgical resection, radiation therapy, and consolidation chemotherapy for unresectable malignant thymomas: Final report. Lung Cancer 2004; 44: 369-379.

53 Berruti A, Borasio P, Gerbino A, et al. Primary chemotherapy with adriamycin, cisplatin, vincristine and cyclophosphamide in locally advanced thymomas: a single institution experience. $\mathrm{Br} J$ Cancer 1999; 81 : 841-845.

54 Attaran S, McCormack D, Pilling J, et al. Which stages of thymoma benefit from adjuvant chemotherapy post-thymectomy? Interact Cardiovasc Thorac Surg 2012; 15: 273-275.

55 Loehrer PJ, Sr, Chen M, Kim K, et al. Cisplatin, doxorubicin, and cyclophosphamide plus thoracic radiation therapy for limited-stage unresectable thymoma: an intergroup trial. J Clin Oncol 1997; 15: 3093-3099.

56 Korst RJ, Bezjak A, Blackmon S, et al. Neoadjuvant chemoradiotherapy for locally advanced thymic tumors: a phase II, multi-institutional clinical trial. J Thorac Cardiovasc Surg 2014; 147: 36-44.

57 Giaccone G, Ardizzoni A, Kirkpatrick A, et al. Cisplatin and etoposide combination chemotherapy for locally advanced or metastatic thymoma. A phase II study of the European Organisation for Research and Treatment of Cancer Lung Cancer Cooperative Group. J Clin Oncol 1996; 14: 814-820. 

1168-1172.

62 Hirai F, Yamanaka T, Taguchi K, et al. A multicenter phase II study of carboplatin and paclitaxel for advanced thymic carcinoma: WJOG4207L. Ann Oncol 2015; 26: 363-368.

63 Okuma Y, Saito M, Hosomi Y, et al. Key components of chemotherapy for thymic malignancies: a systematic review and pooled analysis for anthracycline-, carboplatin- or cisplatin-based chemotherapy. $J$ Cancer Res Clin Oncol 2015; 141: 323-331.

64 Merveilleux du Vignaux C, Dansin E, et al. Systemic therapy in advanced thymic epithelial tumors: Insights from the RYTHMIC prospective cohort. J Thorac Oncol 2018; 13: 1762-1770.

65 Benveniste MF, Korst RJ, Rajan A, et al. A practical guide from the International Thymic Malignancy Interest Group (ITMIG) regarding the radiographic assessment of treatment response of thymic epithelial tumors using modified RECIST criteria. J Thorac Oncol 2014; 9: S119-S124.

66 Sandri A, Cusumano G, Lococo F, et al. Long-term results after treatment for recurrent thymoma: a multicenter analysis. J Thorac Oncol 2014; 9: 1796-1804.

67 Hamaji M, Allen MS, Cassivi SD, et al. The role of surgical management in recurrent thymic tumors. Ann Thorac Surg 2012; 94: 247-254.

68 Mizuno $\mathrm{T}$, Okumura $\mathrm{M}$, Asamura $\mathrm{H}$, et al. Surgical management of recurrent thymic epithelial tumors: a retrospective analysis based on the Japanese nationwide database. J Thorac Oncol 2015; 10: 199-205.

69 Loehrer PJ, Yiannoutsos CT, Dropcho S, et al. A phase II trial of pemetrexed in patients with recurrent thymoma or thymic carcinoma. J Clin Oncol 2006; 24: 7079.

70 Rajan A, Girard N, Marx A. State of the art of genetic alterations in thymic epithelial tumors. J Thorac Oncol 2014; 9: Suppl. 2, S131-S136.

71 Girard N. Thymic malignancies: Emerging systemic therapies. Curr Opin Oncol 2019; 31: 454-460.

72 Girard N, Shen R, Guo T, et al. Comprehensive genomic analysis reveals clinically relevant molecular distinctions between thymic carcinomas and thymomas. Clin Cancer Res 2009; 15: 6790-6799.

73 Maury JM, Merveilleux du Vignaux C, Drevet G, et al. Activation of the mTOR/Akt pathway in thymic epithelial cells derived from thymomas. PLoS One 2019; 14: e0197655.

74 Radovich M, Pickering CR, Felau I, et al. The integrated genomic landscape of thymic epithelial tumors. Cancer Cell 2018; 33: 244-258.

75 Ross JS, Vanden Borre P, Almog N, et al. Comprehensive genomic profiling (CGP) of thymic gland carcinomas. Ann Oncol 2017; 28: Suppl. 5, V595-V596.

76 Zucali PA, De Pas T, Palmieri G, et al. Phase II study of everolimus in patients with thymoma and thymic carcinoma previously treated with cisplatin-based chemotherapy. J Clin Oncol 2018; 36: 342-349.

77 Thomas A, Rajan A, Berman A, et al. Sunitinib in patients with chemotherapy-refractory thymoma and thymic carcinoma: an open-label phase 2 trial. Lancet Oncol 2015; 16: 177-186.

78 Kim YJ, Ock CY, Kim M, et al. Phase II study of sunitinib in patients with thymic carcinoma previously treated with platinum-based chemotherapy (KOSMIC Trial). J Thorac Oncol 2018; 13: S246.

79 Remon J, Girard N, Mazieres J, et al. Sunitinib in patients with advanced thymic malignancies: Cohort from the French RYTHMIC network. Lung Cancer 2016; 97: 99-104.

80 Sato J, Satouchi M, Itoh S, et al. Lenvatinib in patients with advanced or metastatic thymic carcinoma (REMORA): a multicentre, phase 2 trial. Lancet Oncol 2020; 21: 843-850.

81 Nishimura H, Honjo T, Minato N. Facilitation of beta selection and modification of positive selection in the thymus of PD-1-deficient mice. J Exp Med 2000; 191: 891-898.

82 Marchevsky AM, Walts AE. PD-L1, PD-1, CD4, and CD8 expression in neoplastic and nonneoplastic thymus. Hum Pathol 2017; 60: 16-23.

83 Rouquette I, Taranchon-Clermont E, Gilhodes J, et al. Immune biomarkers in thymic epithelial tumors: Expression patterns, prognostic value and comparison of diagnostic tests for PD-L1. Biomark Res 2019; 7: 28.

84 Giaccone G, Kim C, Thompson J, et al. Pembrolizumab in patients with thymic carcinoma: a single-arm, single-centre, phase 2 study. Lancet Oncol 2018; 19: 247-255.

85 Cho J, Kim HS, Ku BM, et al. Pembrolizumab for patients with refractory or relapsed thymic epithelial tumor: An open-label phase II trial. J Clin Oncol 2018; JCO2017773184.

86 Katsuya $\mathrm{Y}$, Horinouchi $\mathrm{H}$, Seto $\mathrm{T}$, et al. Single-arm, multicentre, phase II trial of nivolumab for unresectable or recurrent thymic carcinoma: PRIMER study. Eur J Cancer 2019; 113: $78 \mathrm{e} 86$.

87 Rajan A, Heery CR, Mammen AL, et al. OA18.03: Safety and clinical activity of avelumab (MSB0010718C Anti-PD-L1) in patients with advanced thymic epithelial tumors (TETs). J Thorac Oncol 2017; 12: S130. 